\title{
Effect of Wavelength and Intensity of Light on a-InGaZnO TFTs under Negative Bias Illumination Stress
}

\author{
Woo-Sic Kim, ${ }^{\text {a,z }}$ Yeol-Hyeong Lee, ${ }^{a}$ Yong-Jung Cho, ${ }^{a}$ Byeong-Koo Kim, ${ }^{\text {b }}$ Kyung Tae Park, ${ }^{\text {b }}$ \\ and Ohyun Kim ${ }^{\mathrm{a}}$
}

\author{
${ }^{a}$ Department of Electrical Engineering, Pohang University of Science and Technology, \\ Pohang, Kyungbuk 37673, Korea \\ ${ }^{b}$ IT/Mobile Development Group, LG Display, Gumi, Kyungbuk 39394, Korea
}

\begin{abstract}
We investigated degradation mechanism of a-IGZO TFTs under NBIS with different wavelengths $\lambda$ and intensities $I_{\mathrm{L}}$ of light. Negative gate bias was applied for $4000 \mathrm{~s}$ while drain and source were grounded, and illuminations with $\lambda=450,530$, or $700 \mathrm{~nm}$ were applied. Illumination with photon energy exceeding $\sim 2.3 \mathrm{eV}(530 \mathrm{~nm})$ induced noticeable change in threshold voltage shift $\Delta V_{\text {th }}$, which can be interpreted in terms of ionization of oxygen vacancies $\mathrm{V}_{\mathrm{O}}$. In addition, $I_{\mathrm{L}}$ of blue illumination $(450 \mathrm{~nm})$ was varied from 6 to 200 lux and saturation in $\Delta V_{\text {th }}$ was observed after exceeding a certain $I_{\mathrm{L}}$. We suggest that the saturation occurs because $\mathrm{V}_{\mathrm{O}}$-ionization rate is saturated by outward relaxation of metal atoms in the a-IGZO film.

(C) The Author(s) 2016. Published by ECS. This is an open access article distributed under the terms of the Creative Commons Attribution Non-Commercial No Derivatives 4.0 License (CC BY-NC-ND, http://creativecommons.org/licenses/by-nc-nd/4.0/), which permits non-commercial reuse, distribution, and reproduction in any medium, provided the original work is not changed in any way and is properly cited. For permission for commercial reuse, please email: oa@electrochem.org. [DOI: 10.1149/2.0021701jss] All rights reserved.

(cc) BY-NC-ND
\end{abstract}

Manuscript submitted June 29, 2016; revised manuscript received November 17, 2016. Published December 6, 2016. This was Paper 1246 from the San Diego, California, Meeting of the Society, May 29-June 2, 2016.

Metal oxide-based materials have high carrier mobility, low offcurrent, and good transparency, so they are promising candidates for the channel material of thin film transistors (TFTs). ${ }^{1}$ In particular, amorphous-InGaZnO (a-IGZO) TFTs have excellent properties such as high on/off ratio, good uniformity, and low processing temperature. ${ }^{1}$ However, a-IGZO TFTs exhibit some instability problems.

Stability of a-IGZO TFTs is affected by several factors including bias/current stress, temperature, light illumination and passivation conditions. ${ }^{2-5}$ Among several factors, bias stress is most widely studied because bias is always applied to TFTs in practical display applications. In darkness, the transfer curves of TFTs shift positively when positive bias stress (PBS) is applied to the gate, but shift relatively little when negative bias stress (NBS) is applied. ${ }^{6,7}$ Although a-IGZO TFTs remain stable under NBS, their electrical characteristics degrade when it is combined with illumination, ${ }^{7,8}$ i.e., negative bias illumination stress (NBIS).

Instability of a-IGZO TFTs under NBIS has been widely investigated and reported. ${ }^{7-11}$ Though some papers dealt with the effect of light intensity on reliability of the TFT, ${ }^{12,13}$ the effects of wavelength $\lambda$ and intensity $I_{L}$ of light during NBIS have not been fully explained yet, especially in terms of oxygen vacancy which is crucial factor affecting reliability of a-IGZO TFTs. In this paper, we investigated degradation mechanism of a-IGZO TFTs under NBIS with light of various $\lambda$ and $I_{\mathrm{L}}$. Degradation of a-IGZO TFT under NBIS with different $\lambda$, and the saturation of threshold voltage shift $\Delta V_{\text {th }}$ independent of $I_{\mathrm{L}}$ were identified. We propose that the saturation phenomenon can be explained by restriction in the ionization rate of oxygen vacancy $\mathrm{V}_{\mathrm{O}}$ due to their effect on the structure of a-IGZO.

\section{Method and Measurements}

We fabricated a-IGZO TFTs with bottom gate, back channel etch structure (Fig. 1). A $500 \mathrm{~nm}$-thick and $200 \mathrm{~nm}$-thick $\mathrm{SiO}_{2}$ were used as gate insulator and passivation layer, respectively. The a-IGZO active layer was formed with the channel width/length of $110 \mu \mathrm{m} / 6 \mu \mathrm{m}$. Transfer characteristics of the TFTs were measured after NBIS was applied. For bias stress, negative gate voltage was applied for $4000 \mathrm{~s}$ while drain and source were grounded. Illumination from white LED was passed through blue, green and red filters which have transmission peaks at $\lambda=450 \mathrm{~nm}, 530 \mathrm{~nm}, 700 \mathrm{~nm}$, respectively. In a separate trial, $I_{\mathrm{L}}$ of blue illumination was varied from 6 to 200 lux to investigate how it affects stability.
For transfer characteristics measurements, gate voltage was swept from -20 to $+20 \mathrm{~V}$ at a fixed drain voltage of $0.1 \mathrm{~V}$ for stress durations of 100, 200, 400, 1000, 2000 and 4000s. a-IGZO TFTs were measured at each stress durations without switching off the illumination. Threshold voltage $V_{\text {th }}$ was determined as the gate voltage at which drain current was $10 \mathrm{nA} \times \mathrm{W} / \mathrm{L}$. Measurements were conducted using an Agilent 4156A semiconductor parameter analyzer.

\section{Results and Discussion}

Transfer characteristics were measured after NBS and NBIS with negative gate voltage of $-40 \mathrm{~V}$ were applied at $90^{\circ} \mathrm{C}$ (Fig. 2). In NBIS measurements, illumination sources with different $\lambda$ were used with $I_{\mathrm{L}}=100$ lux after color filter. Shifts in transfer curve under red illumination and in dark condition were not significant (Figs. $2 \mathrm{a}, 2 \mathrm{~b})$. These results are reasonable because a-IGZO is basically ntype material and the energy $(1.78 \mathrm{eV})$ of red illumination was less than the band-gap $(\sim 3.1 \mathrm{eV})$ of a-IGZO ${ }^{14}$ Under green and blue illumination, however, noticeable negative shifts occurred in spite of their low energy (green: $2.3 \mathrm{eV}$; blue: $2.76 \mathrm{eV}$ ) compared to the bandgap of a-IGZO (Figs. 2c, 2d). Shifts were most severe under blue illumination.

To describe the instability mechanism of a-IGZO TFTs under NBIS, charge trapping and sub-gap state generation are usually considered. $^{7-11}$ In a-IGZO, $V_{O}$ forms deep energy states which are located above the valence band maximum with high density. ${ }^{16}$ Therefore, $\mathrm{V}_{\mathrm{O}}$ can be ionized to $\mathrm{V}_{\mathrm{O}}{ }^{2+}$ states by sub-gap illumination and when negative gate bias drives migration of $\mathrm{V}_{\mathrm{O}}{ }^{2+}$ toward the gate insulator/IGZO interface, they can be trapped and result in negative $\Delta V_{\mathrm{th}}{ }^{8}$ In addition, though electron-hole pairs may not be band to

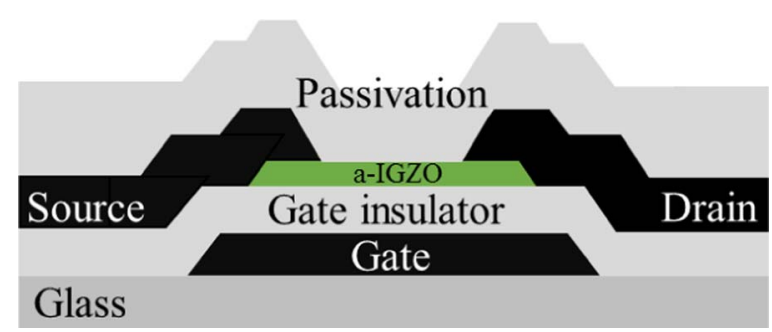

Figure 1. Schematic diagram of fabricated a-IGZO TFT with bottom gate, back channel etch structure. 

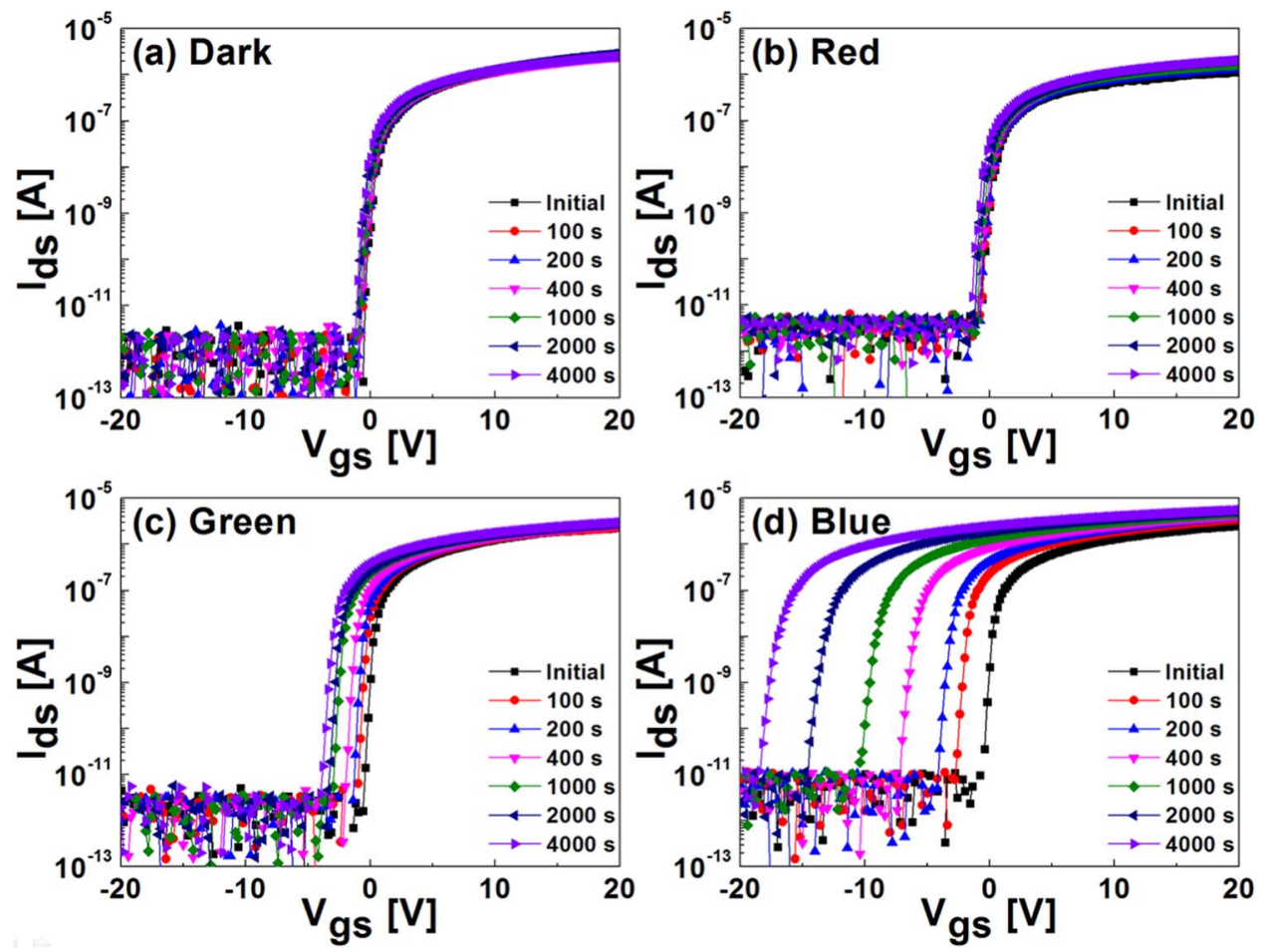

Figure 2. Changes in transfer curves after NBS in (a) dark and NBIS under (b) red, (c) green and (d) blue illumination with $-40 \mathrm{~V}$ gate voltage at $90^{\circ} \mathrm{C}$. $\mathrm{V}_{\mathrm{gs}}$ was swept from -20 to $+20 \mathrm{~V}$ at $\mathrm{V}_{\mathrm{ds}}=0.1 \mathrm{~V}$.

band generated due to low photon energy, trap-assisted hole generation could occur in a-IGZO TFTs. ${ }^{9,14}$ Especially, ionized $V_{O}$ could help generation of holes by capturing electrons excited from valence band via light illumination. ${ }^{14}$ Thus, hole trapping could also occur by virtue of ionized $\mathrm{V}_{\mathrm{O}}$.

Ionization of $\mathrm{V}_{\mathrm{O}}$ to $\mathrm{V}_{\mathrm{O}}{ }^{2+}$ requires energy of $\sim 2.3 \mathrm{eV} ;{ }^{15,17}$ this value is consistent with our results, because both the green and blue illumination which were above and equal to $2.3 \mathrm{eV}$ induced noticeable shifts, whereas red illumination and darkness did not. Especially for blue illumination, the subthreshold slope degraded and the transfer curve shifted significantly (Fig. 2d). Changes in subthreshold slope indicate that sub-gap states were generated during the stress, which is associated with ionized $\mathrm{V}_{\mathrm{O}}$ in a-IGZO TFTs. ${ }^{6,10,15}$

To see the results quantitatively, $\Delta V_{\text {th }}$ values were extracted under various illumination conditions (Fig. 3 ). NBIS under white illumination without filter was tested to be compared with blue illumination. $I_{\mathrm{L}}$ was 4500 lux for white, and 100 lux for blue, green and red.

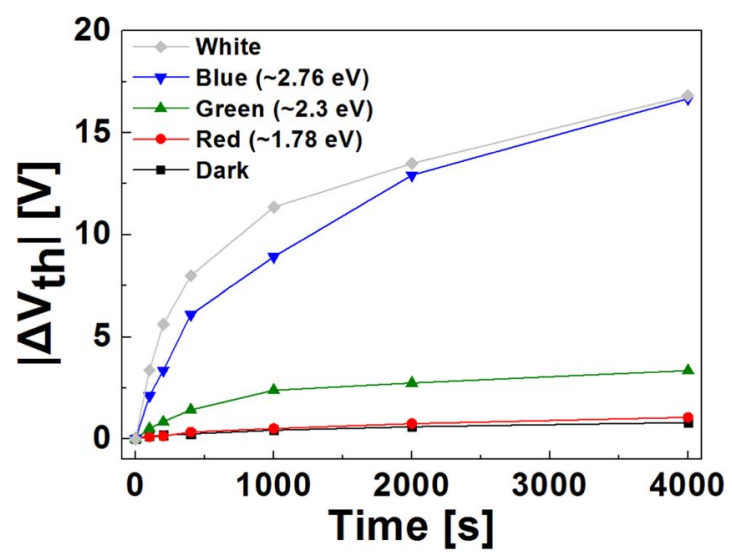

Figure 3. $\Delta \mathrm{V}_{\text {th }}$ vs. stress time in darkness and under white, blue, green, and red illumination.
$\Delta V_{\text {th }}$ after stress for $4000 \mathrm{~s}$ were about $-16.8 \mathrm{~V}$ under white light, $-16.7 \mathrm{~V}$ under blue, $-3.4 \mathrm{~V}$ under green, $-1.1 \mathrm{~V}$ under red and $-0.8 \mathrm{~V}$ in darkness; i.e., despite much lower $\mathrm{I}_{\mathrm{L}}$, blue illumination induced comparable $\Delta V_{\text {th }}$ with that of white light. In addition, $S S$ value changed from $0.2992 \mathrm{~V} / \mathrm{dec}$ to $0.6282 \mathrm{~V} / \mathrm{dec}$ in the blue illumination (Fig. 2d). Number of generated defects $\Delta \mathrm{N}_{\mathrm{t}}$ was calculated to be $2.473 \times 10^{11} / \mathrm{cm}^{2}$ using $\Delta S S=\frac{\Delta \mathrm{N}_{t} \ln (10) k T}{C_{i}}$ equation; ${ }^{4,17}$ this amount of defect would induce only about $-5.73 \mathrm{~V}$ change in $\mathrm{V}_{\text {th }}$, which is lower than the extracted value $(-16.7 \mathrm{~V})$. Therefore, it strongly supports the occurrence of hole trapping.

Hole trapping could occur by trap-assisted hole generation. ${ }^{9,14}$ When $V_{O}$ is ionized by illumination, it would not only result in negative shift of $V_{\text {th }}$ but also act as mid-gap trap state. Photo-excited electrons from the valence band could be captured by ionized $V_{O}$ which acts as mid-gap trap state and as a result, hole could be generated. Therefore, ionized $V_{O}$ would enhance the hole generation and thus, further negative shift of $\mathrm{V}_{\text {th }}$ could occur by hole trapping under NBIS with blue illumination.

$I_{\mathrm{L}}$ of blue illumination was varied from 6 to 200 lux to clarify how it affects stability under same gate bias and temperature of $-40 \mathrm{~V}$ and $90^{\circ} \mathrm{C}$ (Fig. 4). From $I_{\mathrm{L}}=6$ to $I_{\mathrm{L}}=25 \mathrm{lux}, \Delta V_{\text {th }}$ and $\Delta S S$ increased noticeably as $I_{\mathrm{L}}$ increased; this trend occurs because $\mathrm{V}_{\mathrm{O}}{ }^{2+}$ generation rate increased as a result of increase in the number of incident photons with $I_{\mathrm{L}}$. However, increase in $\Delta V_{\text {th }}$ and $\Delta S S$ decelerated at $I_{\mathrm{L}}>25$ lux. $\Delta V_{\text {th }}$ difference between 25 and 200 lux was less than $3.3 \mathrm{~V}$, while it was more than $9 \mathrm{~V}$ between 6 and 25 lux.

$\Delta V_{\text {th }}$ value was expected to increase with increasing $I_{\mathrm{L}}$, because there are more photons in illumination with higher intensity. However, final $(4000 \mathrm{~s}) \Delta V_{\text {th }}$ value saturated after exceeding a certain $I_{\mathrm{L}}$ at several temperatures $T\left(30,60\right.$ and $\left.90^{\circ} \mathrm{C}\right)$ and stress voltages $V_{\text {G.stress }}$ $(-20 \mathrm{~V}$ and $-40 \mathrm{~V})$ (Fig. 5). Saturation values of $\Delta V_{\text {th }}$ increased as $T$ increased because ionization of $\mathrm{V}_{\mathrm{O}}$ is facilitated at elevated $T .^{18}$ In addition, the saturation value of $\Delta V_{\text {th }}$ was approximately twice as large at $-40 \mathrm{~V}$ stress than at $-20 \mathrm{~V}$ stress at all $T$; this result suggests that migration of $\mathrm{V}_{\mathrm{O}}{ }^{2+}$ and holes depends on E-field.

Because $\Delta V_{\text {th }}$ is closely related to migration of ionized $V_{O}$ and holes, $\Delta V_{\text {th }}$ saturation could also be interpreted in terms of $\mathrm{V}_{\mathrm{O}}$ which 

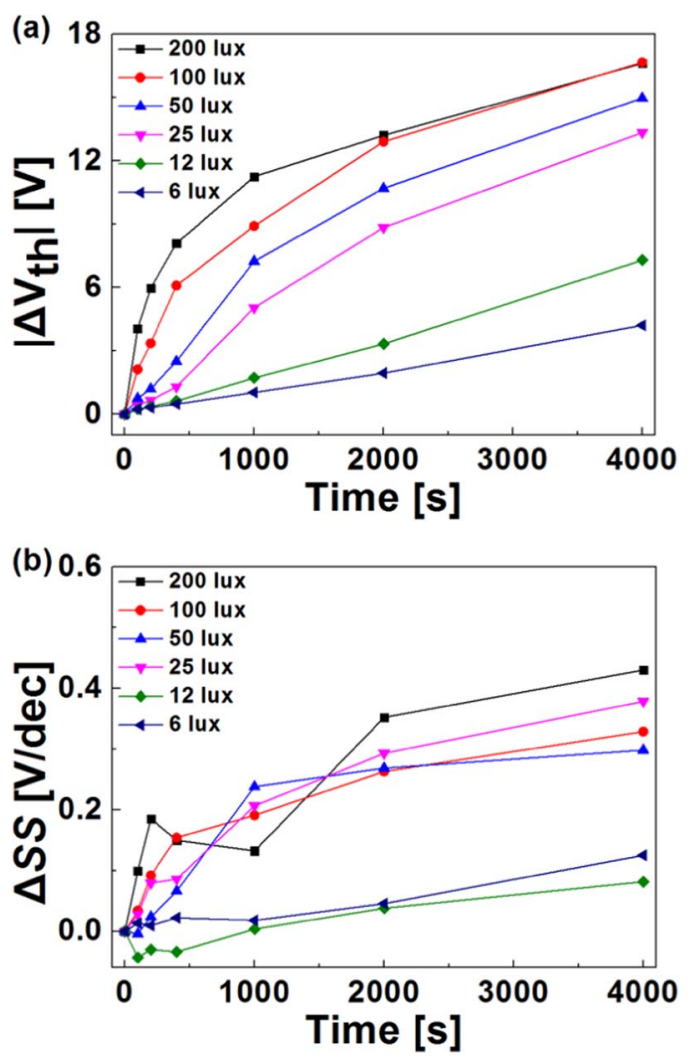

Figure 4. (a) $\Delta V_{\text {th }}$ vs. stress time and (b) $\Delta S S$ vs. stress time with different intensities $I_{\mathrm{L}}$ of blue illumination at $90^{\circ} \mathrm{C}$. Increase in $\Delta \mathrm{V}_{\text {th }}$ decelerated at $I_{\mathrm{L}}>25 \operatorname{lux}$.
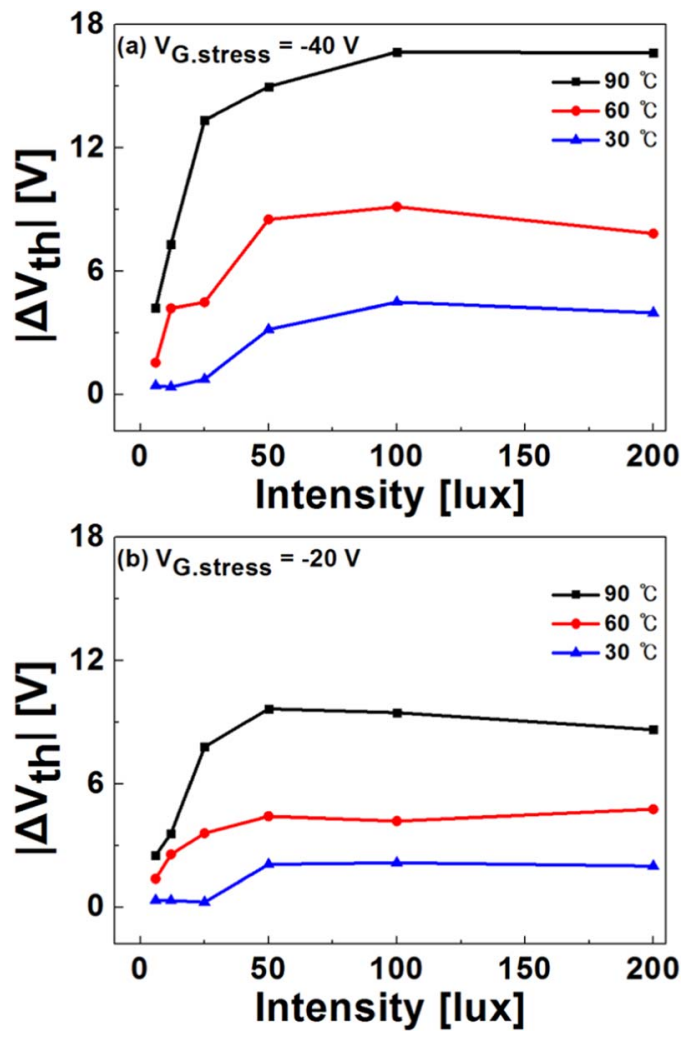

Figure 5. $\Delta \mathrm{V}_{\text {th }}$ vs. intensity with gate bias of (a) $-40 \mathrm{~V}$ and (b) $-20 \mathrm{~V}$ with different temperatures. $\Delta \mathrm{V}_{\text {th }}$ saturated in all stress conditions.
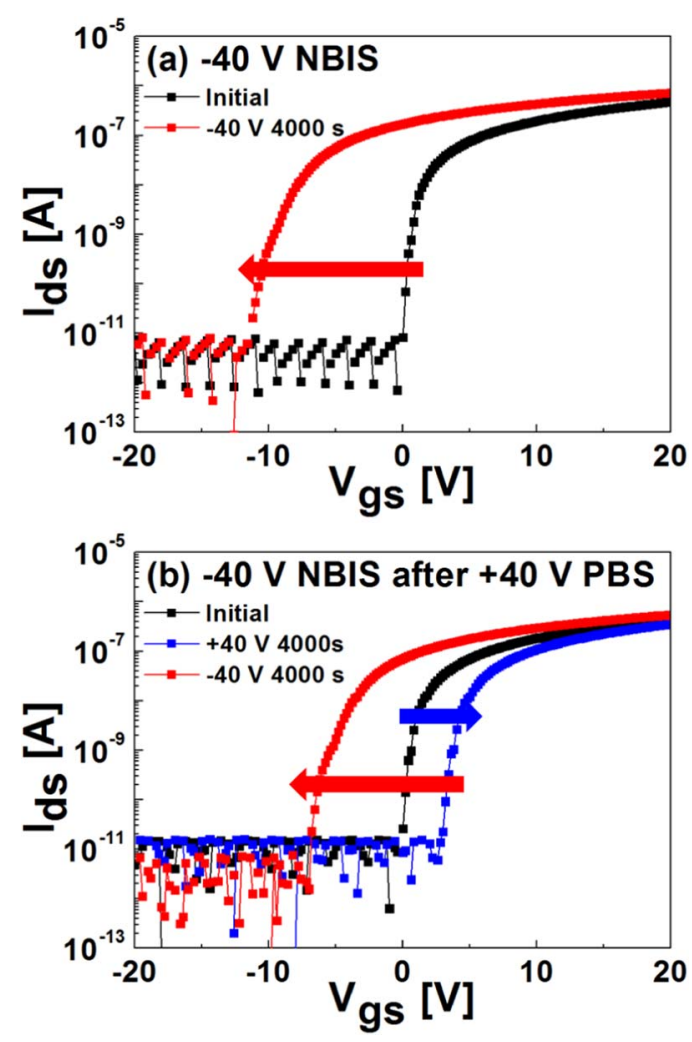

Figure 6. Changes in transfer curves with (a) $-40 \mathrm{~V}$ NBIS and (b) $-40 \mathrm{~V}$ NBIS after $+40 \mathrm{~V}$ PBS at $60^{\circ} \mathrm{C}$. $I_{\mathrm{L}}$ of blue illumination was 100 lux.

is important factor for ionized $\mathrm{V}_{\mathrm{O}}$ and hole generation. Limitation in density of neutral $\mathrm{V}_{\mathrm{O}}$ is not a complete explanation for the $\Delta V_{\text {th }}$ saturation because the increase in the ionization of $\mathrm{V}_{\mathrm{O}}$ as $T$ increased implies that $\mathrm{V}_{\mathrm{O}}$ exists in sufficient amount. There are two possible mechanisms to explain the saturation of $\Delta V_{\mathrm{th}}$. (1) Trappedelectron limitation. $\Delta V_{\text {th }}$ shift saturates because, even though the rate of $\mathrm{V}_{\mathrm{O}}$-ionization increases persistently as $I_{\mathrm{L}}$ increases, the interface hosts a limiting number of trapped electrons, which are necessary for $\mathrm{V}_{\mathrm{O}}{ }^{2+}$ trapping; and (2) $\mathrm{V}_{\mathrm{O}}$-ionization rate saturation. Saturation of $\Delta V_{\text {th }}$ occurs because the ionization rate of indeed $\mathrm{V}_{\mathrm{O}}$ saturates after certain $I_{\mathrm{L}}$.

To verify the former mechanism, we applied PBS shortly before NBIS (blue, $I_{\mathrm{L}}=100$ lux). If $\Delta V_{\text {th }}$ saturation is due to the limited number of electrons at the interface, then if number of electrons trapped at the interface can be increased, the amount of $\Delta V_{\text {th }}$ is expected to increase. PBS increases the number of electrons trapped at the interface. ${ }^{2,6}$ However, application of PBS $(+40 \mathrm{~V})$ just before NBIS $(-40 \mathrm{~V})$ caused almost no difference in $\Delta V_{\text {th }}$ compared to application of just NBIS (Fig. 6). Because $I_{\mathrm{L}}$ (=100 lux) was sufficient to saturate $\Delta V_{\text {th }}$, this result implies that the number of electrons trapped at the interface did not limit $\mathrm{V}_{\mathrm{O}}{ }^{2+}$ trapping.

$\mathrm{V}_{\mathrm{O}}$-ionization rate saturation could be the mechanism of $\Delta V_{\text {th }}$ saturation. When $\mathrm{V}_{\mathrm{O}}$ is ionized, it induces outward relaxation of the neighboring metal atoms. ${ }^{11,19,20}$ Metal ions are positively charged, so they retreat from $V_{O}$ when it is ionized to $V_{O}{ }^{2+}$. At relatively low $I_{\mathrm{L}}$, the ionization rate will increase proportionally to the number of incident photons. On the contrary, after a certain $I_{\mathrm{L}}$, additional photons will not be able to ionize additional $V_{O}$ because ionization will be inhibited by the outwardly-relaxed metal atoms.

The proportion of photons that ionize $V_{O}$ will be highest when outward relaxation has not taken place severely under low intensity (Fig. 7a). Although $\mathrm{V}_{\mathrm{O}}{ }^{2+}$ generated by photo-excitation pushes adjacent metal atoms, it will not have much influence on ionization of others which remain neutral. So there will be a room for 
(a)

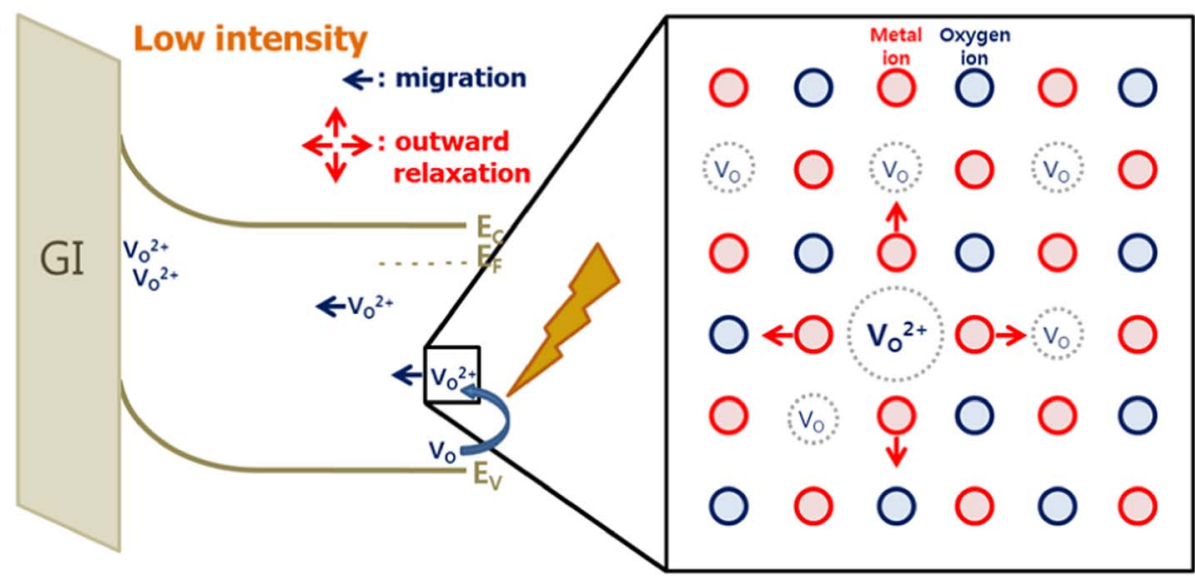

(b)

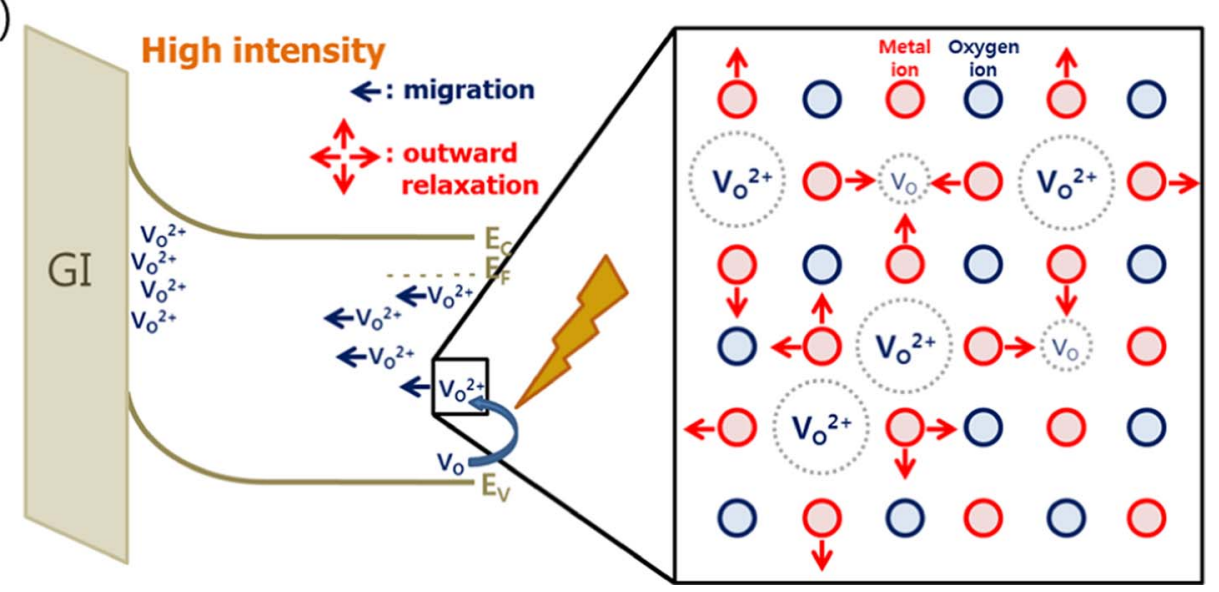

Figure 7. Qualitative description of band diagram and outward relaxation of metal atoms under NBIS with (a) low intensity and (b) high intensity illuminations.

additional $\mathrm{V}_{\mathrm{O}}$ to be ionized and thus, $\Delta V_{\text {th }}$ increases as $I_{\mathrm{L}}$ increases. However, after a certain number of $\mathrm{V}_{\mathrm{O}}$ are ionized, abundant outward relaxation of metal atoms (Fig. 7b) would occur, and inhibit further ionization of remaining neutral $V_{O}$ states even if the number of incident photons increases. So the ionization rate will reach a plateau and as a result, $\Delta V_{\text {th }}$ also saturates even if $I_{\mathrm{L}}$ increases further.

\section{Conclusions}

We investigated how wavelength $\lambda$ and intensity $I_{\mathrm{L}}$ of light affect the degradation in a-IGZO TFTs under NBIS. Illumination with photon energy higher than $2.3 \mathrm{eV}$ was found to have a critical effect on a-IGZO TFTs in NBIS, which was the result of generation and migration of $\mathrm{V}_{\mathrm{O}}{ }^{2+}$ and holes. In addition, $\Delta \mathrm{V}_{\text {th }}$ saturated after $I_{\mathrm{L}}$ exceeded a certain value in NBIS with blue illumination. We suggest that this is a consequence of saturation in $\mathrm{V}_{\mathrm{O}}$-ionization rate due to abundant outward relaxation of metal atoms when $I_{\mathrm{L}}$ exceeds certain level. Though further investigation is required to explain the mechanism quantitatively, our results and proposed mechanism could be a useful guideline in designing display backplanes incorporating a-IGZO TFTs.

\section{Acknowledgments}

This work was supported by LG Display. The authors gratefully acknowledge the technical support of LG Display.

\section{References}

1. K. Nomura, H. Ohta, A. Takagi, T. Kamiya, M. Hirano, and H. Hosono, Nature, 432, 488 (2004).

2. K. H. Ji, J. I. Kim, Y. G. Mo, J. H. Jeong, S. Yang, C. S. Hwang, S. H. K. Park M. K. Ryu, S. Y. Lee, and J. K. Jeong, IEEE Electron Device Lett., 31, 1404 (2010).

3. K.-H. Lee, J. S. Jung, K. S. Son, J. S. Park, T. S. Kim, R. Choi, J. K. Jeong, J.-Y. Kwon, B. Koo, and S. Lee, Appl. Phys. Lett., 95, 232106 (2009).

4. J.-S. Park, J. K. Jeong, H.-J. Chung, Y.-G. Mo, and H. D. Kim, Appl. Phys. Lett., 92, 72104 (2008).

5. M. D. H. Chowdhury, P. Migliorato, and J. Jang, Appl. Phys. Lett., 97, 173506 (2010).

6. J. M. Lee, I. T. Cho, J. H. Lee, and H. I. Kwon, Appl. Phys. Lett., 93, 093504 (2008).

7. H. Oh, S. M. Yoon, M. K. Ryu, C. S. Hwang, S. Yang, and S. H. K. Park, Appl. Phys. Lett., 97, 183502 (2010).

8. H. Oh, S.-M. Yoon, M. K. Ryu, C.-S. Hwang, S. Yang, and S.-H. K. Park, Appl. Phys. Lett., 98, 033504 (2011)

9. Y. Ueoka, Y. Ishikawa, J. P. Bermundo, H. Yamazaki, S. Urakawa, M. Fujii, M. Horita, and Y. Uraoka, ECS J. Solid State Sci. Technol., 3, Q3001 (2014).

10. J. Gwang Um, M. Mativenga, P. Migliorato, and J. Jang, Appl. Phys. Lett., 101, 113504 (2012).

11. B. Ryu, H. K. Noh, E. A. Choi, and K. J. Chang, Appl. Phys. Lett., 97, 022108 (2010)

12. S. Y. Lee, J. Y. Kwon, and M. K. Han, IEEE Trans. Electron Devices, 60, 2574 (2013).

13. S. Y. Han, K. T. Park, C. Kim, S. Jeon, S.-H. Yang, and H.-S. Kong, ACS Appl. Mater. Interfaces, 7, 15442 (2015).

14. M. P. Hung, D. Wang, and M. Furuta, ECS Solid State Lett., 4, Q66 (2015).

15. K. Nomura, T. Kamiya, and H. Hosono, J. Soc. Inf. Disp., 18, 789 (2010).

16. K. Nomura, T. Kamiya, H. Yanagi, E. Ikenaga, K. Yang, K. Kobayashi, M. Hirano, and H. Hosono, Appl. Phys. Lett., 92, 202117 (2008).

17. X. Huang, C. Wu, H. Lu, F. Ren, Q. Xu, H. Ou, R. Zhang, and Y. Zheng, Appl. Phys. Lett., 100, 243505 (2012).

18. S. H. Kuk, S. Y. Lee, S. J. Kim, B. Kim, S. J. Park, J. Y. Kwon, and M. K. Han, IEEE Electron Device Lett., 33(9), 1279 (2012).

19. A. Janotti and C. G. Van de Walle, Appl. Phys. Lett., 87, 122102 (2005).

20. H.-K. Noh, K. Chang, B. Ryu, and W.-J. Lee, Phys. Rev. B, 84, 115205 (2011). 